\title{
Opportunities and Challenges Faced by Graduate Students in Entrepreneurship
}

\author{
Gang Li \\ Graduate School of Jilin Agricultural University, China
}

\begin{abstract}
The 17th National Congress of the Communist Party of China put forward the development strategy of "improving independent innovation ability and building innovative country" and "implementing the expansion of employment and promoting the employment driven by entrepreneurship". Graduate students are the main force of science and technology innovation in our country in the future. It is a senior reserve talented person of our country's economic and social construction. It is necessary to cultivate their innovation and entrepreneurial ability. This paper, starting from the cultivation of innovative talents and the current research of our country student's severe employment situation, using literature, comparative method, and summary to analyze development status and existing problems of our graduate student's entrepreneurship. On the basis of this analysis, propose relevant implementation strategy of graduate's entrepreneurship from the three aspects of country, universities and individuals, so as to promote graduates entrepreneurship.
\end{abstract}

Keywords: Employment; Graduate students; Entrepreneurship.

\section{Introduction}

Graduate students, with profound theoretical background, constitute the main force of China's scientific and technological innovation, who are the important driving force for China's economic development and social progress. However, the current China's postgraduate education exists the tendency of emphasizing knowledge inheritance, while ignoring the cultivation of ability and science and technology innovation [1]. In addition, most of the graduate has a light awareness of entrepreneurship in general and the competitiveness of employment is gradually increasing. As a result, employment pressure of graduates becomes heavier and heavier. In view of this, we must have a clear understanding of current employment situation and the status of entrepreneurship. In recent years, the employment situation of graduate students in our country is more and more serious, the employment rate of graduate students in Jilin province in 2007 is $78 \%$, and the first employment rate of graduate students in Liaoning province in 2008 is $76.57 \%$. Since 1999, the number of student enrolled has been increasing with a high proportion of $26.9 \%$ for many years [2]. In recent years, the number of the graduate students hits record highs. According to the data of the statistical yearbook of the Ministry of education, changes of the number of the graduate from 2004 to 2008 are as follows figure 1. Moreover, the areas that the graduate will choose after graduation are also explored, as shown in figure 2 .

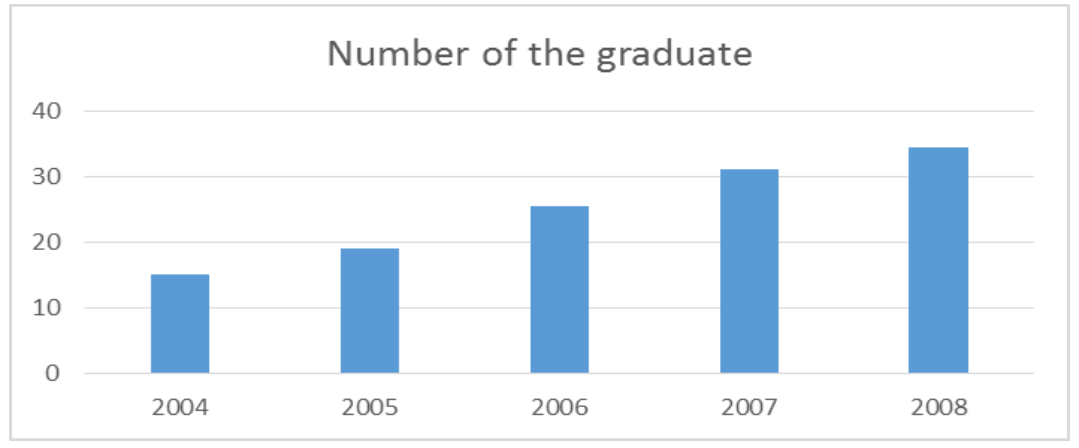

Figure 1 Change of the number of the graduate 


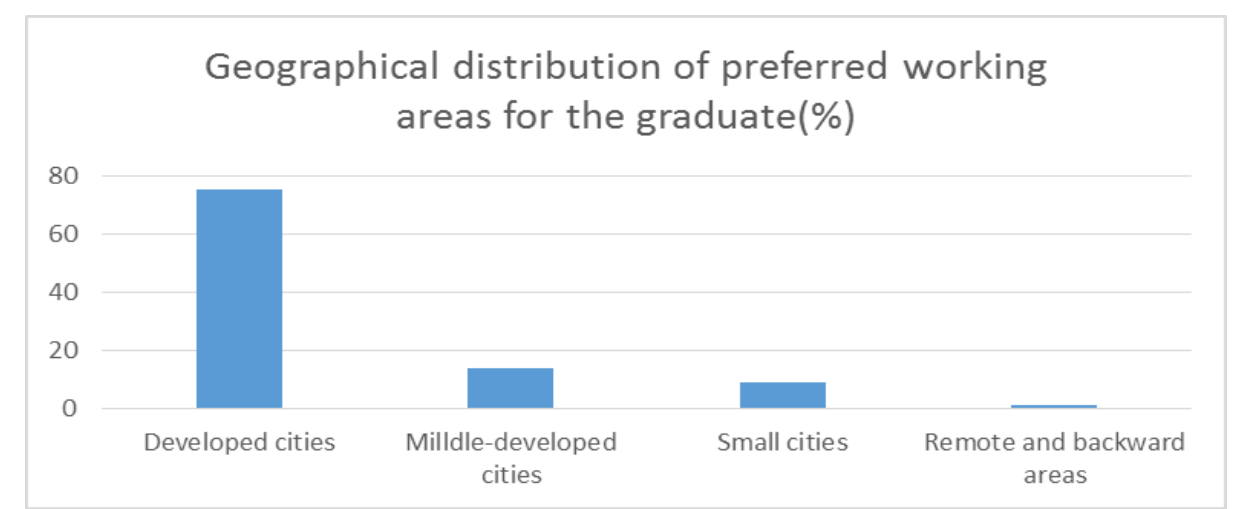

Figure 2 Geographical distribution of preferred working areas for the graduate

\section{Connotation of Graduates Entrepreneurship}

As for the definition of entrepreneurship, there is no unified understanding of the theoretical field formed. People usually think that entrepreneurship means to start a new business. This is the explanation from a narrow sense of entrepreneurship, instead, entrepreneurship has a broader meaning. It can refer to all the social activities that create achievement. Management professor $\mathrm{Yu}$ Yihong of Fudan University believes that entrepreneurship is a process of discovering and capturing opportunities and thus create new products or services, so as to achieve its potential value. Tsinghua University Professor, deputy director of China Business Research Center, Lei Jiaxiao thinks entrepreneurship is the process or activity of "find, create and take advantage of business opportunities to combine factors of production, and create their own careers, so as to obtain the commercial success [3]. He stressed that the purpose of entrepreneurship is to achieve commercial success and gain commercial profits. Stevenson and other professors of Harvard Business School believe that entrepreneurship is a behavior driven by perceived opportunity, rather than a behavior controlled by existing resources. Awareness of entrepreneurship is psychological tendency that graduate become persistent in the entrepreneurial activities, including the need, motivation, interests, beliefs and world view. It is the most basic internal driving force for graduate to start a business, which determines the graduate student understanding of entrepreneurial activity and recognition degree [4]. However, in traditional education, there are rare education involving the cultivation of graduate students entrepreneurial consciousness, which makes graduate students can only passively apply for a job rather than actively take the initiative to create jobs. The following is the conclusion of a questionnaire survey of our graduate student's choice after graduation (figure 3 ).

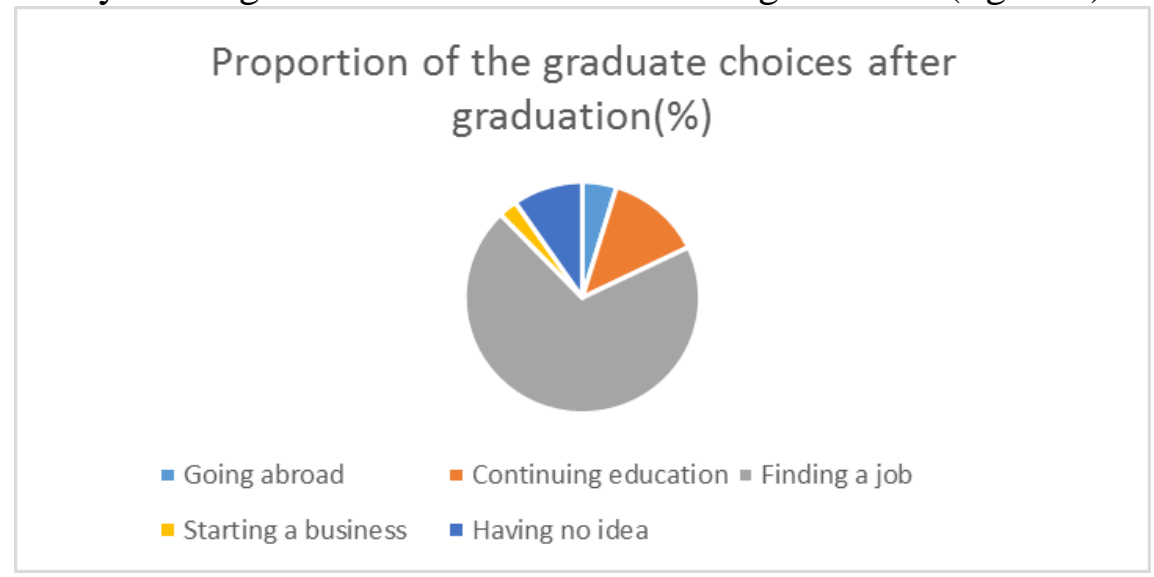

Figure 3 the graduate's choices after graduation 


\section{Opportunities for Graduate Students' Entrepreneurship}

Graduate Entrepreneurship can not only alleviate the current severe employment situation, improve technology conversion rate, promote the comprehensive development of the graduate, which has objective necessity. Moreover, graduate students have the advantages of mastering advanced technology, mature social psychological, and supported by supervisor and so on. Compared to College students, they have any feasibility, the specific analysis is as follows.

\subsection{Profound Theoretical Foundation}

After many years' accumulation, graduate students have a profound theoretical foundation. And knowledge they exposed to in Colleges and Universities in depth is deeper than that exposed to by the College students. And the knowledge is mostly in cutting-edge, which is the greatest wealth and biggest advantage for them to start a business. These profound and cutting-edge knowledge may contain more business opportunities, and it is not easy to be found in general. Only those who understand the knowledge and technology can make use of them to start up a business. Therefore, as long as they are good at discovering and capturing, they will have more opportunities for entrepreneurship, easy to realization of high-tech venture.

\subsection{Mature Social Psychology and Excellent Communicating Ability}

Entrepreneurship is a high risk, and high return social activities. In the process of entrepreneurial especially the initial stage, it is full of hardships and failures, which requires entrepreneurs has perseverance and the courage to face the failure. Graduate students are older than the College students so that they have more social experience, and after many years of education, compared with the students, their social psychology and mental are more mature, which is the advantage of their entrepreneurship. In addition, the graduate students also have a lot of social activities, which objectively exercise their social interaction. It is an essential comprehensive ability in the entrepreneurial process. In a word, no matter in the social psychology or the social intercourse ability, compared with the College students, they are more suitable for entrepreneurship.

\subsection{Good External Environment}

With the support from their mentor, entrepreneurship for graduate students is more likely to succeed. Most of the mentor of graduate students are experts in their field of study. They not only have a profound knowledge and skills, but also a wide range of social relations. With their support, it is easier for the graduate students in the choice of entrepreneurial projects, business plan formulation, business organization and venture financing so that their entrepreneurial will be easily succeeded. And this is the advantage for entrepreneurship that the College students do not have. Graduate Entrepreneurship has an obvious advertising effect, which makes it easier to start a business. Graduate students are the top talents in the education system, who have a very high reputation in the community [5]. Therefore, when they choose to do start up a business, there will be more people supporting them, even more people to cooperate with and join in them. Hunan University business management professional research students Liangming recycling package attracted the franchisee, which is a powerful proof. Countries and Universities have introduced a number of policies to encourage graduate entrepreneurship, which provides convenience for graduate entrepreneurship. In recent years, national and local levels of government and Universities have issued many incentives to encourage the entrepreneurship, including fees relief measures, tax incentives, graduate students can have suspension for entrepreneurship measures and so on. Objectively, it provides great convenience and support for the graduate students' entrepreneurship.

\section{Challenges for Graduate Students' Entrepreneurship}

\subsection{Lack of Country' Supporting for Entrepreneurship}

In recent years, with the increasingly serious employment situation, our country has recognized the necessity of entrepreneurship for graduate students, and also provide support for graduate students' entrepreneurship in some aspects. But on the whole, the support is not enough, which is mainly manifested in the following aspects. First of all, policy support by countries for graduate students' 
entrepreneurship has limitations. Our country has recognized the necessity of entrepreneurship for graduate students, also introduced a number of policies to support graduate students' entrepreneurship. However, we should see that there are great limitations in our country' policies and measures to encourage graduate students entrepreneurship. It mainly refers to the low practicality of policy inconvenient for implementation. Some of the policies have too high requirements on the requested object [6]. As a result, most of the graduate students needed to be funded miss the preferential policies because of they do not meet the conditions of the recipients. Secondly, the promotion of graduate students' entrepreneurship is not enough. In foreign countries, especially in the United States, the country make full use of various media to promote entrepreneurship so that the good atmosphere has formed "everyone advocates entrepreneurship, everyone wants to entrepreneurship" in the society, which has extremely important role in cultivating people's awareness of entrepreneurship. While in China, although the promotion is done, but is not enough [7]. There is no atmosphere of advocating entrepreneurship formed in the whole society.

\subsection{Insufficiency of Attention to Entrepreneurship from Schools, Teachers and Graduate Students}

In the traditional mode of education, graduate cultivation target is to develop academic and applied talents, and their employment channels are engaged in research work in universities, research institutes and other institutions. It has not caused enough attention for graduate entrepreneurship from schools, teachers and graduate students themselves. Up to now, the entrepreneurship in Colleges and universities is mostly for undergraduate. At the graduate level, entrepreneurship education carries out some entrepreneurship courses mainly for students of School of economics and management. There are quite rare schools set up entrepreneurship related courses. Additionally, education method of entrepreneurship for graduate students is rather single. The majority of schools just carry out some entrepreneurship seminars, entrepreneurship forum and other activities for school students, and then notify the interested graduate students to participate, rather than specifically carry out some activities or related courses for graduate students.

\subsection{Weakness of Entrepreneurial Culture of Graduate Students}

At present, some Colleges carry out the entrepreneurship education for graduate students, but because it started late, most entrepreneurship education is not systematical, theory is disconnected with practice, and on the whole school entrepreneurial culture atmosphere is weak. The specific performance is as follows. First of all, public opinion promotion does not attach enough importance to the entrepreneurship. The school newspaper, campus radio, Internet and other publicity channels tend to attach importance to the promotion to government officials and outstanding workers, while typical of self-employed is not too much concerned about, which may will leave an illusion for graduate students that work step by step is the right path and independent business is not recognized by schools and society. Second, entrepreneurship education is single in form. The main entrepreneurship education method includes report and entrepreneurship plan competition, which still have great uncertainty. The entrepreneurship report in many schools is relatively low in level, and entrepreneurship plan competition is characterized by short time, little object, and "elite" phenomenon, which cannot meet the demand for entrepreneurship. In short, the current university has not yet formed a strong campus entrepreneurial culture.

\section{Conclusion}

Nowadays, the graduate employment situation is increasingly grim. This paper, from the perspective of alleviating the current severe employment situation, promoting the comprehensive development of the graduate, and improving science and technology conversion rate, discusses the objective necessity of entrepreneurship for graduate students, points out the theoretical and practical significance of graduate students' entrepreneurship in the current severe employment situation [8]. In addition, this paper summarizes and analyzes development condition of entrepreneurship. It points out the objective fact that our graduate students entrepreneurial is still in the exploration period. 
Although we have made some achievements, we should see that there are still many problems currently in the graduate entrepreneurship. At present, graduate entrepreneurship has not caused enough attention from the University, teachers and graduate colleges and universities haven't done relevant reform about graduate students' entrepreneurship. Additionally, entrepreneurial cultural atmosphere is weak. Therefore, it is necessary for schools, governments, and most importantly graduate students themselves to cooperate with each other. Only by the joint efforts can graduate students' entrepreneurship have a better development.

\section{References}

[1] Arasti Z, Falavarjani M K, Imanipour N. A study of teaching methods in entrepreneurship education for graduate students [J]. Higher Education Studies, 2012, 2(1): 2.

[2] Rasli A, Khan S U R, Malekifar S, et al. Factors affecting entrepreneurial intention among graduate students of Universiti Teknologi Malaysia [J]. International Journal of Business and Social Science, 2013, 4(2).

[3] Dinis A, do Paço A, Rodrigues R G. Does entrepreneurship education to teenagers have different impacts over time: some evidences based on an Entrepreneurship Education Programmed on Mozambique Youth[C]//ICSB World Conference Proceedings? International Council for Small business (ICSB), 2014: 1.

[4] Rideout E C, Gray D O. Does entrepreneurship education really work? A review and methodological critique of the empirical literature on the effects of university-based entrepreneurship education [J]. Journal of Small Business Management, 2013, 51(3): 329-351.

[5] Alexander C, Groen A J. Summer school as a tool of education in entrepreneurship theory: a case study[C]//ICSB World Conference Proceedings. International Council for Small business (ICSB), 2014: 1 .

[6] Bozeman B, Fay D, Slade C P. Research collaboration in universities and academic entrepreneurship: the-state-of-the-art [J]. The Journal of Technology Transfer, 2013, 38(1): 1-67.

[7] Lima E, Lopes R M, and Nassif V. Opportunities to improve entrepreneurship education: Contributions considering Brazilian challenges [J]. Journal of Small Business Management, 2015, 53(4): 1033-1051.

[8] Drucker P. Innovation and entrepreneurship [M]. Routledge, 2014. 